\title{
Long-term Pilocarpine Treatment Improves Salivary Flow in Irradiated Mice
}

\author{
Akie Taniguchi ${ }^{1,2}$, Taketo Susa ${ }^{1,2}$, Hiroshi Kogo ${ }^{2}$, Akiko Iizuka-Kogo ${ }^{2}$, Satoshi Yokoo $^{1}$ \\ and Toshiyuki Matsuzaki ${ }^{2}$
}

${ }^{I}$ Department of Oral and Maxillofacial Surgery, and Plastic Surgery, Gunma University Graduate School of Medicine, Maebashi, Gunma and 'Department of Anatomy and Cell Biology, Gunma University Graduate School of Medicine, Maebashi, Gunma, Japan

Received March 18, 2019; accepted May 28, 2019; published online June 19, 2019

\begin{abstract}
Radiation therapy for head and neck cancer frequently causes salivary gland dysfunction. Pilocarpine is a clinically approved and effective drug that induces saliva secretion, thereby keeping the oral mucosa moist and reducing discomfort in patients, but the effect is transient. We expected that this drug also has beneficial long-term effects that maintain the integrity of salivary glands by reducing, for instance, apoptosis. Here, we examined the effects of long-term pilocarpine administration in irradiated mice. The results indicated that long-term pilocarpine administration significantly improved salivary flow in irradiated mice, suggesting the potential beneficial effects of long-term administration. To elucidate the underlying mechanism, we analyzed the histology, apoptosis, and proliferation of acinar cells, and the expression of functional membrane proteins such as transmembrane member $16 \mathrm{~A}$, aquaporin-5, and $\mathrm{Na}-\mathrm{K}-\mathrm{Cl}$ cotransporter. Long-term pilocarpine treatment seemed to decrease irradiation-induced apoptosis, although the change was not statistically significant. The present results indicated that long-term administration of pilocarpine has beneficial effects on salivary flow in irradiated mice, and suggested that long-term administration possibly decreases apoptosis in irradiated salivary glands.
\end{abstract}

Key words: radiation, xerostomia, pilocarpine, salivary glands, apoptosis

\section{Introduction}

Radiation therapy is frequently used for head and neck cancer treatment $[5,32]$. However, damage to healthy salivary glands often induces xerostomia (dry mouth) [24]. Patients with xerostomia have uncomfortable symptoms such as oral discomfort or pain, resulting in difficulties in eating, speaking, and swallowing, and increased risk of dental caries or oral infection $[9,12]$. These conditions may lead to depression and a decline in quality of life [6]; therefore, effective therapies are needed. Pilocarpine is clinically used for relieving xerostomia symptoms [16, 27, 40]. Pilocarpine is a muscarinic cholinergic agonist that stimu-

Correspondence to: Toshiyuki Matsuzaki, Department of Anatomy and Cell Biology, Gunma University Graduate School of Medicine, 3-39-22, Showa-machi, Maebashi, Gunma 371-8511, Japan.

E-mail: matoshi@gunma-u.ac.jp lates transient salivary secretion $[1,11,33]$. Stimulation of the muscarinic-3 acetylcholine receptor (M3 receptor) by cholinergic agents such as pilocarpine activates transmembrane member 16A (TMEM16A) on the apical membrane of acinar cells in a calcium-dependent manner, inducing the secretion of $\mathrm{Cl}^{-}$into the lumen [4,34]. Along with $\mathrm{Cl}^{-}$ secretion, $\mathrm{Na}^{+}$moves through the paracellular pathway to the acinar lumen, resulting in water secretion through aquaporin-5 (AQP5) on the apical membrane $[25,28]$ and through the paracellular pathway [30]. At the same time, $\mathrm{Cl}^{-}$is supplied by the $\mathrm{Na}-\mathrm{K}-\mathrm{Cl}$ cotransporter (NKCC1) on the basolateral membrane of acinar cells [10]. Pilocarpine is prescribed for its acute and short-term effect on inducing salivary fluid secretion. Long-term pilocarpine administration in patients with radiation therapy-induced xerostomia is effective for restoring salivary flow and relieving symptoms $[16,27,40]$. This suggests that, in addition to its tran- 
sient effect on stimulating salivary secretion, pilocarpine has long-lasting beneficial activity against irradiationinduced salivary gland dysfunction. The underlying mechanism of this potential beneficial effect, however, is not understood. The aim of the present study was to investigate the underlying mechanism as well as to ascertain the beneficial effect of long-term pilocarpine treatment using an animal model. Coppes et al. [8] examined the effect of one-time administration of pilocarpine before irradiation with 15 gray (Gy) on salivary flow in rats, and the results showed that salivary flow improved for up to 60 days compared with that in untreated irradiated animals. As long-term pilocarpine administration in patients with radiation therapy-induced xerostomia is reported to effective for salivary flow and relieving symptoms [16, 27, 40], daily administration of pilocarpine in irradiated animals was expected to more effectively ameliorate salivary flow than one-time administration of pilocarpine over 60 days. Moreover, the effective prevention from salivary gland dysfunction induced by irradiation was expected to facilitate the analysis of the underlying mechanism. In the present study, therefore, we examined the effect of daily administration of pilocarpine from 5 days before to 63 days after irradiation on salivary flow. Then the underlying mechanism was investigated by measuring apoptosis, cellular proliferation, and the expression of the functional membrane proteins TMEM16A, AQP5, and NKCC1.

\section{Materials and Methods}

\section{Animals}

Similar to previous studies [2, 22, 23, 26, 31, 37, 39], female animals were used in this study. Nine-week-old (body weight, 30-32 g) female ICR mice were purchased from SLC Inc. (Shizuoka, Japan). All animal experiments were performed in compliance with the NIH Guide for the Care and Use of Laboratory Animals and approved by the Animal Care and Experimentation Committee, Gunma University, Showa Campus (approval no. 17-026). Mice were maintained using normal chow and water during the experiment. (Fig. 1).

Thirty mice were randomly divided into three groups

1) Control group: CTR; untreated $(n=10)$.

2) Irradiated group: IRD; irradiated without pilocarpine administration $(n=10)$.

3) Irradiated and pilocarpine-treated group: IRD+Pilo; irradiated and treated with pilocarpine daily from 5 days before to 63 days after irradiation $(n=10)$. Pilocarpine hydrochloride (Sigma-Aldrich P6503, St Louis, MO, USA) was diluted to $0.25 \mathrm{mg} / \mathrm{ml}$ in physiological saline (Otsuka Pharmaceutical, Tokyo, Japan), and $0.1 \mathrm{ml}$ was orally administered with a Teflon tube under isoflurane anesthesia. The dose of pilocarpine used in this study was determined as follows. Considering that patients usually receive $5 \mathrm{mg}$ of pilocarpine hydrochloride three times a day and

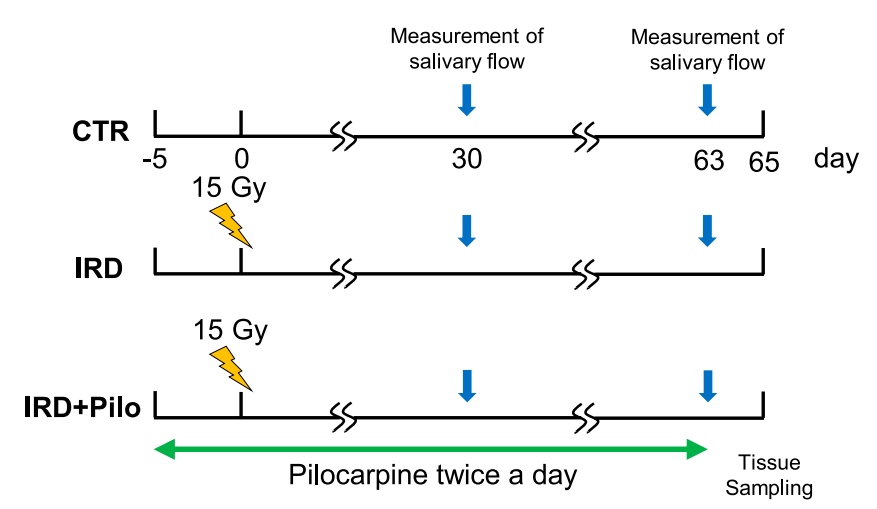

Fig. 1. Animal groups and administration procedure. Animals were divided into three groups. CTR: control group. IRD: irradiated group. IRD+Pilo: irradiated and pilocarpine-administered group. Pilocarpine administration was initiated 5 days before irradiation. Salivary flow was measured at 30 and 63 days after irradiation. Tissue sampling was performed at 65 days after irradiation.

assuming a patient's weight of $60 \mathrm{~kg}$, the dose will be 8.3 $\mu \mathrm{g} / 100 \mathrm{~g}$. Considering that the weight of mice at the start of the experiment was approximately $30 \mathrm{~g}$, the dose should be $2.5 \mu \mathrm{g}$. In the present study, mice were treated with a 10fold higher dose of $25 \mu \mathrm{g}$ twice a day, morning and night.

\section{Irradiation}

Before irradiation, mice were anesthetized with an intraperitoneal injection of $10 \mathrm{mg} / 100 \mathrm{~g}$ of body weight (bw) ketamine and $1 \mathrm{mg} / 100 \mathrm{~g}$ of bw xylazine. A $20 \times 30$ $\mathrm{mm}$ window was opened on a $1 \mathrm{~mm}$ thick lead plate, and only the area including the submandibular and parotid glands was exposed. Irradiation with a single dose of $15 \mathrm{~Gy}$ was delivered using an X-ray unit (Faxitron MultiRad 225; Acrobio, Tokyo, Japan).

\section{Measurement of stimulated salivary flow}

The amount of saliva secreted from all salivary glands after stimulation with pilocarpine was measured at 30 and 63 days after irradiation. Oral administration of pilocarpine to IRD+Pilo animals was omitted on the day of measuring salivary flow. All mice were weighed and anesthetized by an intraperitoneal injection of $10 \mathrm{mg} / 100 \mathrm{~g}$ of bw ketamine and $1 \mathrm{mg} / 100 \mathrm{~g}$ of bw xylazine. After anesthesia, $0.5 \mathrm{mg} / \mathrm{kg}$ of bw pilocarpine was injected subcutaneously to induce salivary secretion. Total saliva was collected from the mouth and transferred to a $5 \mathrm{ml}$ micro-tube connected to a polyethylene tube and an aspirator (VACUSIP; Integra Biosciences, Hudson, NH, USA) for $10 \mathrm{~min}$ after pilocarpine injection. The amount of saliva per body weight was calculated and statistically analyzed.

\section{Tissue sampling}

Animals were sacrificed and tissues were collected at 65 days after irradiation as follows: for histochemical analyses, four randomly chosen mice from each group were deeply anesthetized with $10 \mathrm{mg} / 100 \mathrm{~g}$ of bw ketamine 
and $1 \mathrm{mg} / 100 \mathrm{~g}$ of bw xylazine, and perfused with $4 \%$ paraformaldehyde in $0.1 \mathrm{M}$ phosphate buffer ( $\mathrm{pH} 7.4$ ) following physiological saline (Otsuka Pharmaceutical). Whole parotid and submandibular gland tissues were excised and incubated in the same fixative overnight. After washing with PBS, tissue blocks were dehydrated through a series of graded ethanol, cleared in xylene, and embedded in paraffin.

\section{Hematoxylin-eosin staining}

Paraffin sections of $4 \mu \mathrm{m}$ thickness were cut and mounted on adhesive glass slides (Platinum; Matsunami, Osaka, Japan). Sections were deparaffinized with xylene, rehydrated, and washed with PBS. Sections were stained with Mayer's hematoxylin (30002; Muto Pure Chemicals, Tokyo, Japan) and eosin (32002; Muto Pure Chemicals), and observed under an AxioPhoto2 microscope (Zeiss, Overkochen, Germany). Images were captured using a DP72 digital camera (Olympus, Tokyo, Japan) and CellSens standard software (Olympus).

\section{Antibodies and specificity}

Rabbit anti-AQP5 (AffRaTM14) and guinea pig antiAQP5 (AffGPTM41) were developed and characterized in our laboratory [29, 28]. Rabbit anti-cleaved caspase-3 (Asp175) (9661; Cell Signaling, Beverly, MA, USA) [35], rabbit anti-Ki67 (ab16667; Abcam, Cambridge, MA, USA), rabbit anti-NKCC1 (ab59791; Abcam), and rabbit anti-TMEM16A (ab53212; Abcam) were purchased as indicated. Secondary antibodies used were HRP-conjugated goat anti-rabbit (P0448; DAKO, Glostrup, Denmark), Rhodamine Red-X-conjugated donkey anti-rabbit (711295-152; Jackson ImmunoResearch, West Grove, PA, USA), Alexa 488-conjugated donkey anti-rabbit (A21206; Life Technologies), and Alexa 488-conjugated donkey antiguinea pig antibodies, which were made by conjugating Alexa 488 to donkey anti-guinea pig IgG (706-005-148; Jackson ImmunoResearch) by our laboratory using Alexa 488 protein labeling kit (A10235; Life Technologies). The specificities of commercial antibodies against cleaved caspase-3, Ki67, TMEM16A, and NKCC1 were confirmed by immunoblotting and immunofluorescence as described below.

\section{Antibody to cleaved caspase-3}

HeLa cells were cultured on plastic dishes for immunoblotting or on collagen-coated coverslips for immunofluorescence, and then treated with $30 \mu \mathrm{M}$ cisplatin to induce apoptosis $[15,20,41]$ or vehicle (Dulbecco's PBS) for $13 \mathrm{hr}$ at $37^{\circ} \mathrm{C}$.

For immunoblotting, cells were scraped in PBS and centrifuged, and the pellet was homogenized in PBS containing a protease inhibitor (Complete Mini; Roche Applied Science, Mannheim, Germany). Samples were denatured by boiling for $3 \mathrm{~min}$ in an equal volume of buffer containing $50 \mathrm{mM}$ Tris- $\mathrm{HCl}$ (pH 7.5), 4\% SDS, $300 \mathrm{mM}$ dithiothreitol, $50 \%$ glycerol, and $0.01 \%$ bromophenol blue. Proteins were separated by SDS-PAGE in a 5-20\% polyacrylamide gel (EHR T520L; ATTO, Tokyo, Japan), and transferred to a polyvinylidene difluoride membrane (Immobilon-PSQ; Merck Millipore, Billerica, MA, USA). MagicMark XP western protein standard (LC5602; Life Technologies, Grand Island, NY, USA) and Novex sharp pre-stained protein standard (LC5800; Life Technologies) were used as the molecular weight standards. After blocking with StartingBlock T20 (TBS) blocking buffer (37543; Thermo Scientific) for $30 \mathrm{~min}$, the membrane was incubated with rabbit anti-cleaved caspase-3 diluted at 1:50,000 at $4^{\circ} \mathrm{C}$. After washing with Tris-based buffer $(10 \mathrm{mM}$ Tris- $\mathrm{HCl}, 150 \mathrm{mM} \mathrm{NaCl}, 1 \mathrm{mM}$ EDTA, and $0.1 \%$ Triton $\mathrm{X}-100$ ), the membrane was incubated with HRP-conjugated goat anti-rabbit $\operatorname{IgG}$ at room temperature for $90 \mathrm{~min}$. Visualization was performed using ECL Prime western blotting detection reagent (RPN2232; GE Healthcare, Buckinghamshire, UK), and images were captured with a CCD camera (ImageQuant LAS4000; GE Healthcare).

For immunofluorescence, cells on coverslips were fixed with $4 \%$ paraformaldehyde in $0.1 \mathrm{M}$ phosphate buffer (pH 7.4) for $20 \mathrm{~min}$, and then incubated sequentially with rabbit anti-cleaved caspase-3 diluted at 1:500 and Alexa 488-conjugated donkey anti-rabbit antibody diluted in $0.1 \%$ saponin-PBS.

\section{Antibody to Ki67}

HeLa cells were cultured on plastic dishes for immunoblotting or on collagen-coated coverslips for immunofluorescence for $21 \mathrm{hr}$ at $37^{\circ} \mathrm{C}$ to almost $40 \%$ confluency.

For immunoblotting, cells were scraped in PBS and centrifuged, and the pellet was homogenized in RIPA buffer $(150 \mathrm{mM} \mathrm{NaCl}, 0.5 \%$ sodium deoxycholate, and $1 \%$ NP-40 in $50 \mathrm{mM}$ Tris-HCl pH 7.5) containing a protease inhibitor. Samples were denatured by boiling for $10 \mathrm{~min}$, processed for SDS-PAGE, immunoblotted with rabbit antiKi67 (1:50,000), and visualized with ECL western blotting detection reagent.

For immunofluorescence, cells on the coverslips were fixed with $4 \%$ paraformaldehyde in $0.1 \mathrm{M}$ phosphate buffer (pH 7.4) for $20 \mathrm{~min}$, treated with $0.1 \%$ Triton $\mathrm{X}-100$ in PBS for $10 \mathrm{~min}$, and then incubated sequentially with rabbit anti-Ki67 (1:500) and Alexa 488-conjugated donkey antirabbit antibody.

\section{Antibody to TMEM16A and NKCC1}

Normal female ICR mouse parotid glands were homogenized in PBS containing a protease inhibitor, and then centrifuged at $800 \mathrm{~g}$ for $5 \mathrm{~min}$ to remove the nuclei and tissue debris. The sample was denatured by boiling for 3 min, processed for SDS-PAGE, immunoblotted with rabbit anti-TMEM16A $(1: 50,000)$ or rabbit anti-NKCC1 $(1: 50,000)$, and visualized with ECL Prime western blotting detection reagent. 


\section{Enzyme immunohistochemistry and cell counting}

Deparaffinized sections were rehydrated and washed with PBS. For antigen retrieval, sections were placed in 20 $\mathrm{mM}$ Tris- $\mathrm{HCl}$ buffer $(\mathrm{pH} 9.0)$ and heated in a microwave oven (MI-77; Azumaya, Tokyo, Japan) for $30 \mathrm{~min}$ at $97^{\circ} \mathrm{C}$. After washing with PBS, endogenous peroxidase activity was blocked with $0.5 \% \mathrm{H}_{2} \mathrm{O}_{2}$ in methanol for $30 \mathrm{~min}$ at room temperature. After washing with PBS, sections were sequentially incubated with $1 \%$ bovine serum albumin in PBS to block nonspecific binding of antibodies, and the primary antibody, rabbit anti-cleaved caspase-3 (1:500) or rabbit anti-Ki67 (1:500), at $4^{\circ} \mathrm{C}$ overnight. The secondary antibody used was HRP-goat anti-rabbit IgG (P0448; DAKO, Glostrup, Denmark). After washing with PBS, the $\mathrm{DAB}$ reaction was carried out in a solution of $\mathrm{DAB}$ (ImmPACT DAB peroxidase substrate; Vector Laboratories, Burlingame, CA, USA) for 30 seconds at room temperature, washed, and then counterstained with Mayer's hematoxylin.

Four animals from each group were analyzed. Two slices from each animal were stained, and specimens were observed under an Axiophot2 light microscope with a $40 \times$ objective lens. Five areas from each slice were randomly selected, and images were captured with a DP72 digital camera (Olympus). Cleaved caspase-3-positive acinar cells or Ki67-positive acinar cells and total acinar cells within each area were counted. The numbers of positive acinar cells and total acinar cells from five areas were finally added, and the ratio of positive to total acinar cells was obtained for each animal. The mean values of the positive ratio from four animals from each group were calculated and statistically analyzed $(n=4)$.

\section{Immunofluorescence analysis}

Paraffin sections of $4 \mu \mathrm{m}$ thickness were cut and mounted on adhesive glass slides (Platinum; Matsunami, Osaka, Japan). Sections were deparaffinized with xylene, rehydrated, and washed with PBS. For antigen retrieval, sections were placed in $20 \mathrm{mM}$ Tris- $\mathrm{HCl}$ buffer ( $\mathrm{pH} 9.0$ ) and heated in a microwave oven (MI-77; Azumaya) for 30 min at $97^{\circ} \mathrm{C}$. After washing with PBS, sections were incubated with $5 \%$ normal donkey serum-PBS for blocking nonspecific binding of antibodies, followed by sequential incubation in primary and secondary antibodies. For nuclear staining, 4',6-diamidino-2-phenylindole (DAPI) was added to the mixture of secondary antibodies. Specimens were mounted with Vectashield mounting medium (Vector Laboratories), and examined with a BX62 microscope equipped with Nomarski differential interferencecontrast and epifluorescence optics (Olympus, Tokyo, Japan). Images were captured using a CoolSNAP K4 CCD camera (Photometrics, Tucson, AZ, USA) and MetaMorph software version 6.1 (Molecular Devices, Silicon Valley, CA, USA).

\section{Histochemical controls} AQP5

Antibody solution was preincubated with an antigen peptide $(10 \mu \mathrm{g} / \mathrm{ml})$.

\section{Cleaved caspase-3, Ki67, TMEM16A, and NKCC1}

Antibody was omitted from primary antibody solution.

\section{Statistical analyses}

Data are presented as the mean \pm SD. Statistical analyses were performed using IBM SPSS Statistics 25 . Two-tailed unpaired $t$-test was used for all analyses. In the first step, comparison of salivary flow between the IRD and CTR group was performed to confirm the establishment of irradiated salivary gland dysfunction mice. When a significant decrease in the IRD group compared with the CTR group was confirmed, then comparison between IRD+Pilo and IRD group was performed to see the effect of pilocarpine. Similarly, comparison of the positive ratio of cleaved caspase-3 for apoptosis or Ki67 for cellular proliferation between the IRD and CTR group was performed to see whether these are changed by irradiation or not. Then, comparison between IRD+Pilo and IRD group was performed to see the effect of pilocarpine. A $P$ value of $<0.05$ was considered significant.

\section{Results}

\section{Stimulation of salivary flow}

To evaluate salivary gland function, pilocarpinestimulated salivary flow was measured as described previously because it is difficult to measure resting salivary flow in mice [7, 8, 10, 21, 25, 39]. At 30 and 63 days, pilocarpine-stimulated salivary flow per body weight was significantly lower in the IRD group than in the CTR group (Fig. 2A and B), demonstrating the establishment of irradiation-induced salivary gland dysfunction model mice as described previously $[7,8,39]$. In response to long-term administration of pilocarpine, salivary flow was significantly higher in the IRD+Pilo group than in the IRD group at 30 and 63 days (Fig. 2A and B).

\section{Histological changes}

The parotid glands of the IRD group (Fig. 3B) showed a decrease in acinar cells and an increase in interstitial spaces and fibers compared with the CTR group (Fig. 3A), which may have been caused by chronic inflammation, because many inflammatory cells were evident (Fig. 3B). No differences in parotid glands were observed between the IRD (Fig. 3B) and IRD+Pilo (Fig. 3C) groups. No histological changes were observed in the submandibular glands except for a slight enlargement of acini in the IRD group (Fig. 3E) compared with those in the CTR group (Fig. 3D). The submandibular glands did not differ between the IRD (Fig. 3E) and IRD+Pilo (Fig. 3F) groups. 
A

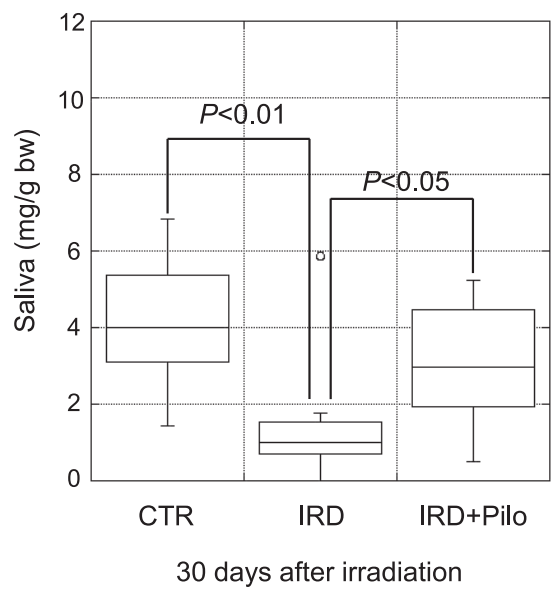

B

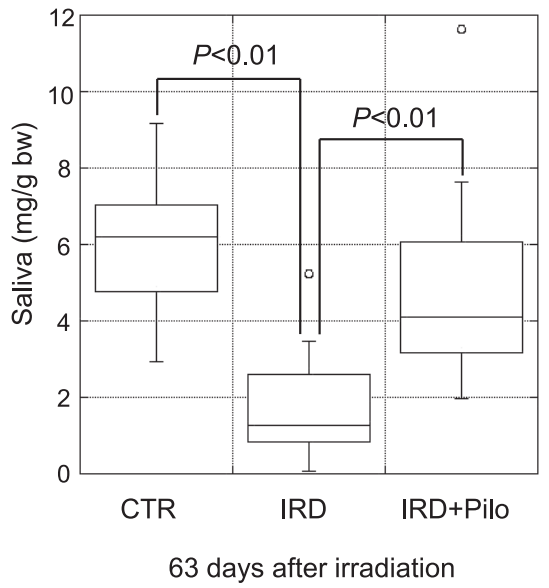

Fig. 2. Salivary flow. Pilocarpine-stimulated salivary flow per body weight at 30 days (A) and 63 days (B) after irradiation. Data are expressed as dot and box plots.
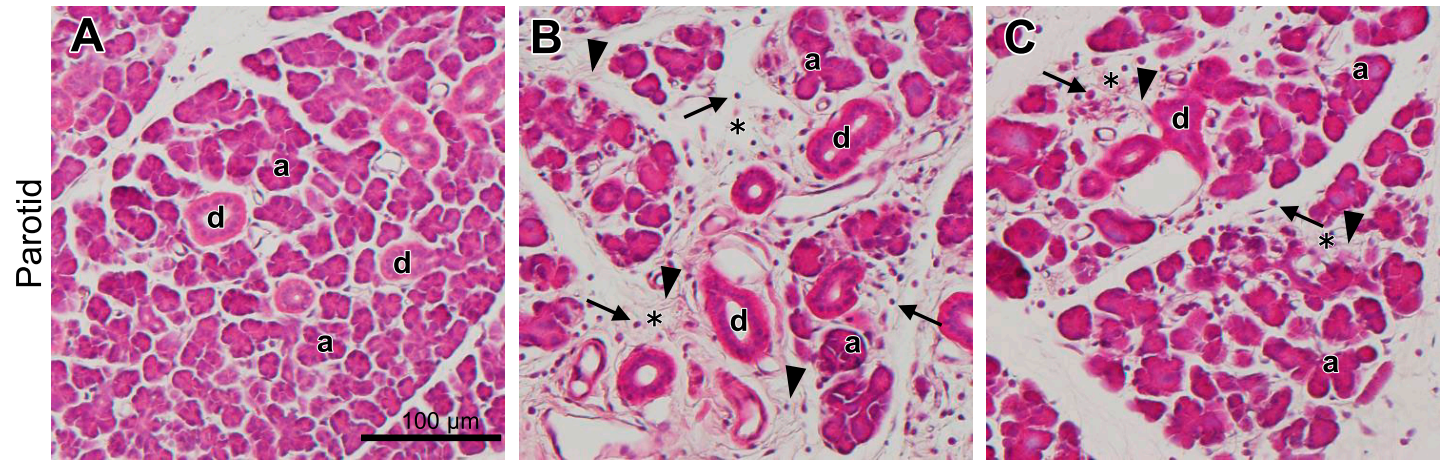

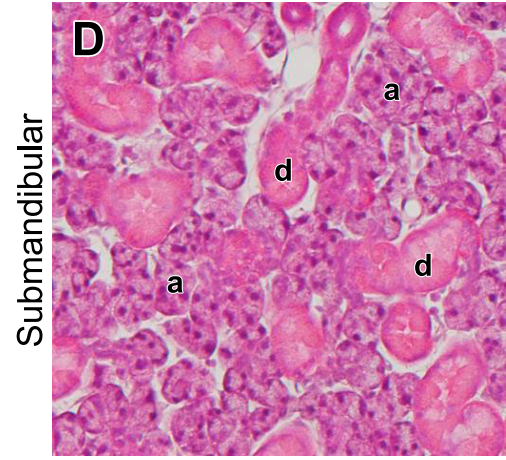

CTR

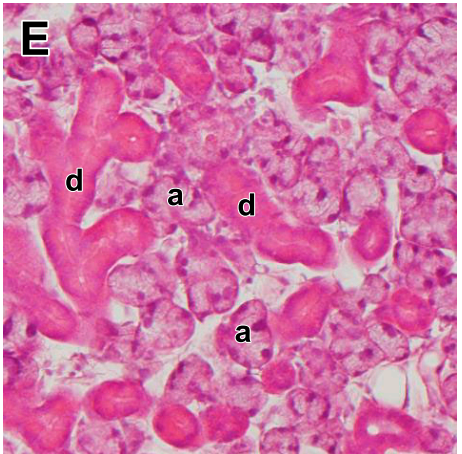

IRD

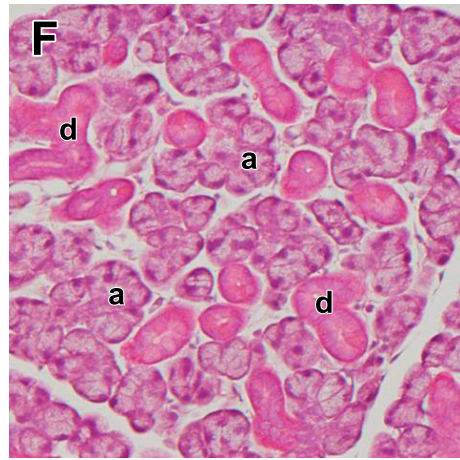

IRD+Pilo

Fig. 3. Hematoxylin-eosin staining. Typical images of the parotid $(\mathbf{A}, \mathbf{B}$, and $\mathbf{C})$ and submandibular $(\mathbf{D}, \mathbf{E}$, and $\mathbf{F})$ glands from each group are shown. Some of acini and ducts are indicated by "a" and "d", respectively. Mononuclear infiltrates and increased interstitial fibers in increased interstitial spaces (asterisks) are indicated by arrows and arrowheads, respectively, in $\mathbf{B}$ and $\mathbf{C}$.

\section{Apoptosis and cell proliferation}

To clarify the mechanism underlying the beneficial effect of long-term administration of pilocarpine, we focused on apoptosis and cellular proliferation and examined the changes of cleaved caspase- 3 and Ki67. Tissue slices from four animals from each group were immunolabeled and representative images are shown in Figures 4 and 5. Labeling for cleaved caspase-3 was seen in both parotid and submandibular glands from all groups, in which the labeling was chiefly present in acinar cells intracellularly (Fig. 4). Positive cells in the submandibular gland seemed to be fewer than those in the parotid gland. Labeling for Ki67 was seen in the nuclei of acinar, ductal, and interstitial cells of both parotid and submandibular glands (Fig. 5). We focused on the change of cleaved caspase-3 or Ki67 in the secretory acini; therefore, ratios of positive 

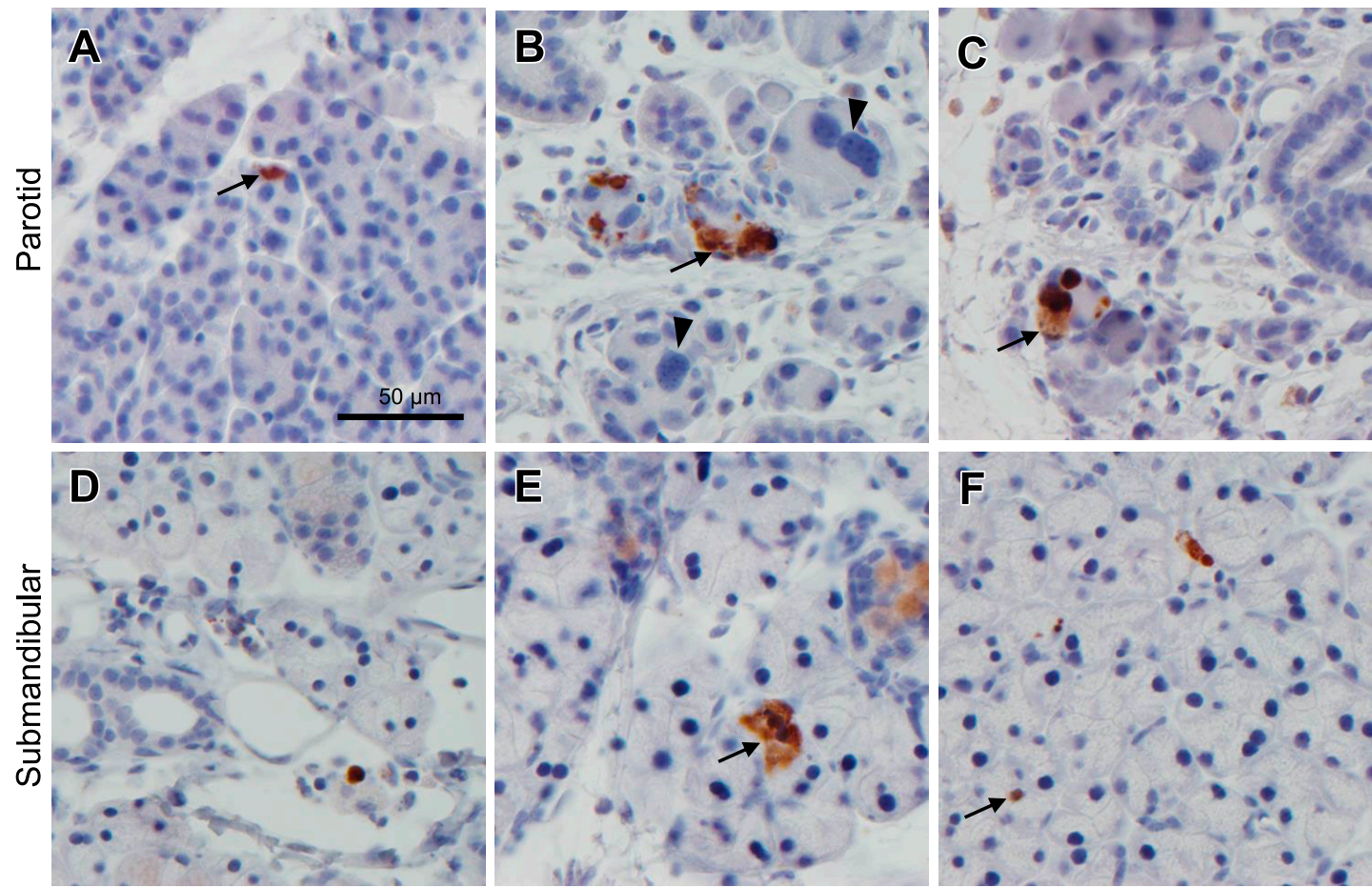

CTR

IRD

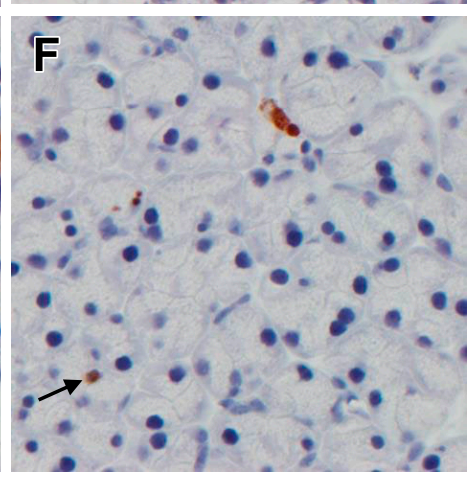

IRD+Pilo

Fig. 4. Enzyme immunohistochemistry for cleaved caspase-3. Typical images of the parotid $(\mathbf{A}, \mathbf{B}$, and $\mathbf{C})$ and submandibular $(\mathbf{D}, \mathbf{E}$, and $\mathbf{F})$ glands from each group are shown. Arrows indicate positive acinar cells. Arrowheads indicate abnormally enlarged parotid acinar cells with enlarged nuclei.
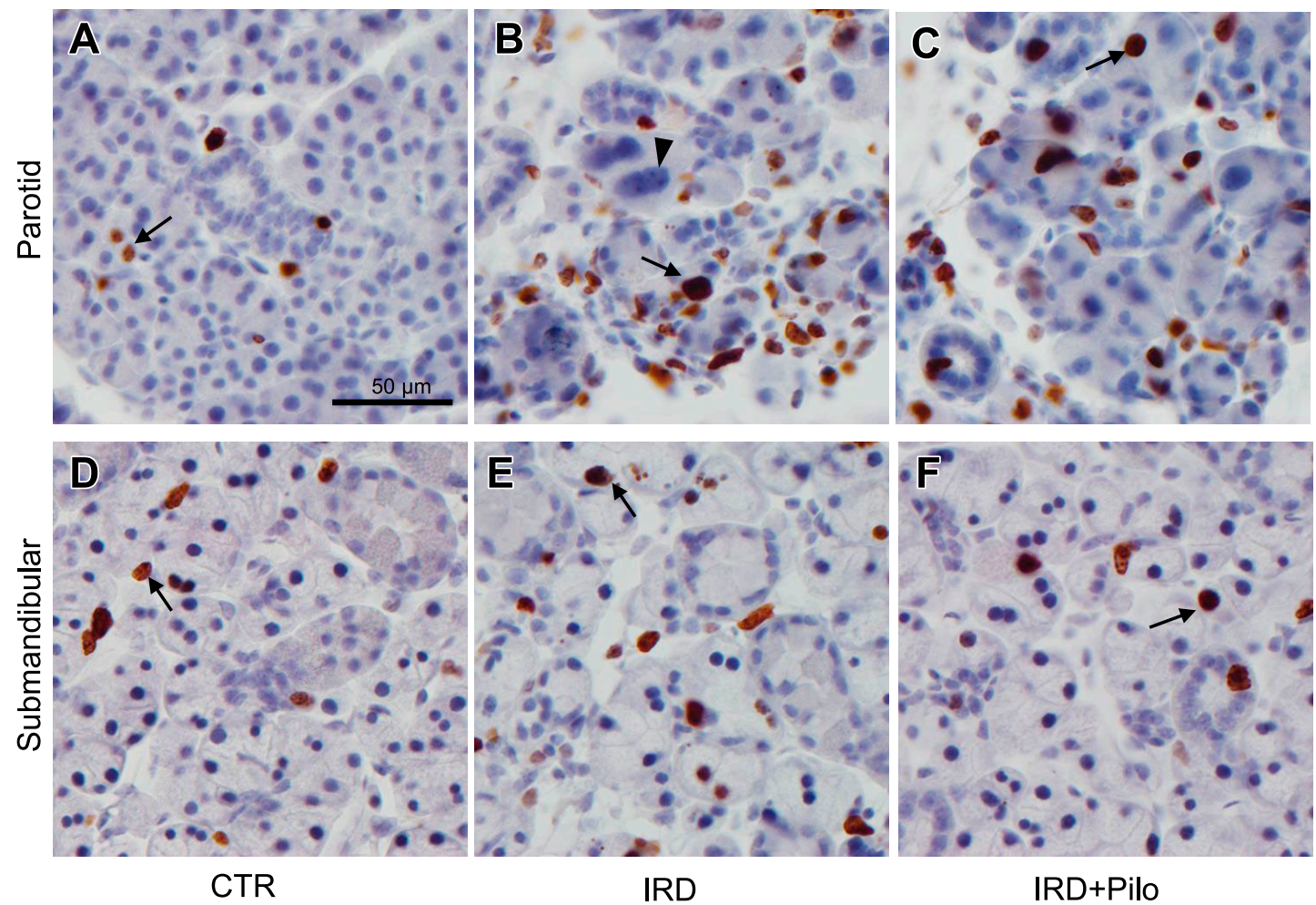

Fig. 5. Enzyme immunohistochemistry for Ki67. Typical images of the parotid (A, B, and C) and submandibular (D, E, and F) glands from each group are shown. Arrows indicate positive acinar cells. Arrowhead indicates abnormally enlarged parotid acinar cells with enlarged nuclei. 
acinar cells to total acinar cells was calculated and compared these ratios between the IRD and CTR groups as described in the materials and methods section and results are shown in Table 1 . The positive cleaved caspase- 3 ratio was significantly higher in the parotid and submandibular glands of the IRD group than in those of the CTR groups. Then we compared the positive cleaved caspase- 3 ratio in the IRD+Pilo group with that in the IRD group to see whether the pilocarpine treatment has a beneficial effect against apoptosis or not. The positive cleaved caspase-3 ratio in both glands was lower in the IRD+Pilo group than in the IRD group, although the change was not statistically significant. The Ki67-positive ratio was significantly higher in the parotid glands of the IRD group than in those of the CTR group. When we compared the Ki67-positive ratio in the parotid glands between the IRD+Pilo and IRD groups, the ratio was lower in the IRD+Pilo group than in the IRD group without statistical significance. Similar changes were seen in Ki67 in the submandibular glands without statistical significance.

\section{Functional channels and transporter}

To determine whether the beneficial effect of pilocarpine was related to functional channels and transporters involved in salivary fluid secretion, we analyzed the expression of TMEM16A, AQP5, and NKCC1 by immunofluorescence microscopy (Figs. 6, 7, and 8, respectively).
Table 1. Positive ratio of cleaved caspase-3 or Ki67

\begin{tabular}{lllc}
\hline & CTR $(n=4)$ & IRD $(n=4)$ & IRD+Pilo $(n=4)$ \\
\hline Cleaved caspase-3 & & & \\
$\quad$ Parotid gland & $0.14 \pm 0.13$ & $3.38 \pm 1.97^{\text {a }}$ & $1.38 \pm 0.56$ \\
$\quad$ Submandibular gland & $0.16 \pm 0.12$ & $1.62 \pm 0.58^{\mathrm{b}}$ & $1.14 \pm 0.81$ \\
Ki67 & & & \\
$\quad$ Parotid gland & $9.42 \pm 9.26$ & $36.2 \pm 2.88^{\mathrm{c}}$ & $33.4 \pm 10.9$ \\
$\quad$ Submandibular gland & $5.65 \pm 1.59$ & $16.7 \pm 7.78$ & $8.20 \pm 1.42$ \\
\hline
\end{tabular}

Ratio of positive acinar cells to total acinar cells was calculated as described in the materials and methods section.

Values (\%) are mean $\pm \mathrm{SD}$.

Two-tailed unpaired t-test was used to compare IRD with CTR and IRD + Pilo with IRD.

${ }^{\text {a }} P=0.04$ compared with CTR.

${ }^{\text {b }} P=0.01$ compared with CTR.

${ }^{c} P=0.002$ compared with CTR.

TMEM16A was localized to the apical membrane of acinar cells in both parotid and submandibular glands from the CTR group (Fig. 6A and D), consistent with a previous study [34]. AQP5 is mainly localized in the apical membrane and partially in the basolateral membrane of acinar cells in both parotid and submandibular glands from the CTR group (Fig. 7A and D), consistent with previous studies [28, 29]. NKCC1 seemed to localize to both apical and basolateral membranes (Fig. 8A and D); therefore, we performed the double labeling with anti-AQP5 and
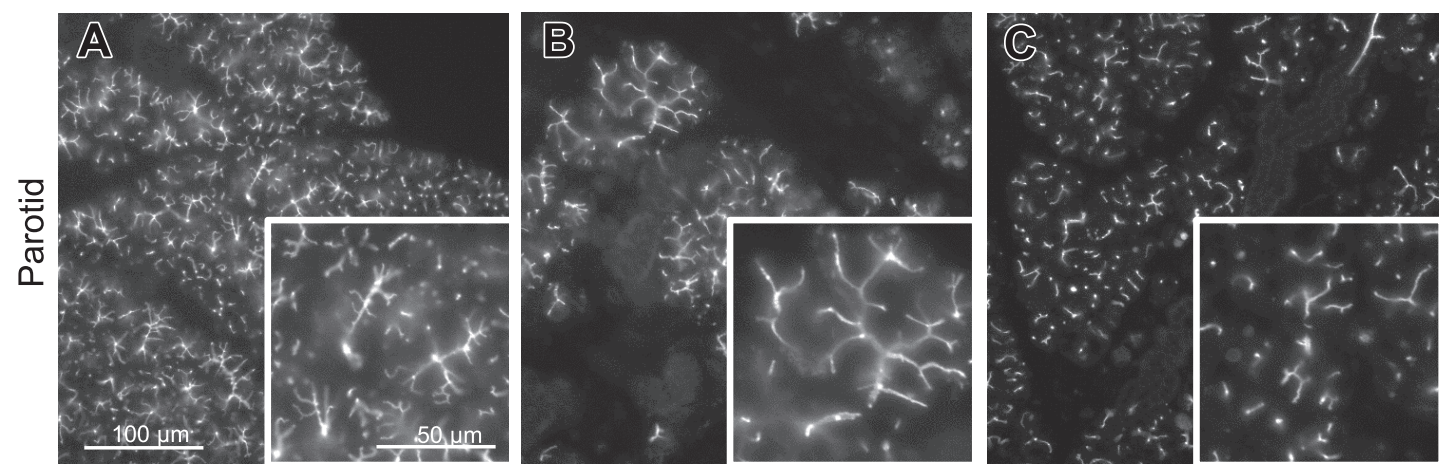

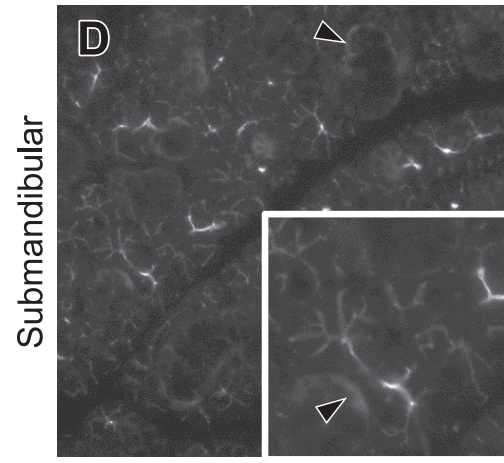

CTR

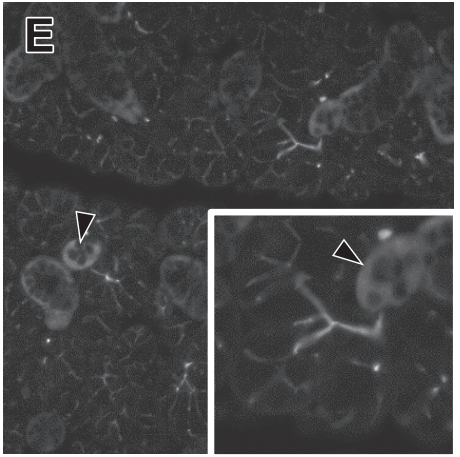

IRD

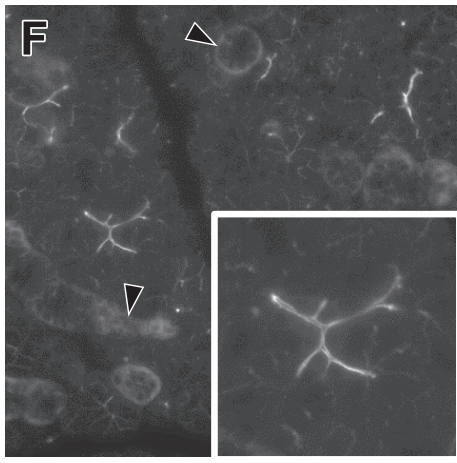

IRD+Pilo

Fig. 6. Immunofluorescence analysis of TMEM16A. Typical fluorescence images of the parotid (A, B, and C) and submandibular (D, E, and F) glands from each group are shown. Each image was captured under identical conditions. Insets show higher magnification views of a section of individual images. Arrowheads indicate nonspecific labeling in ducts (see Fig. 12) 

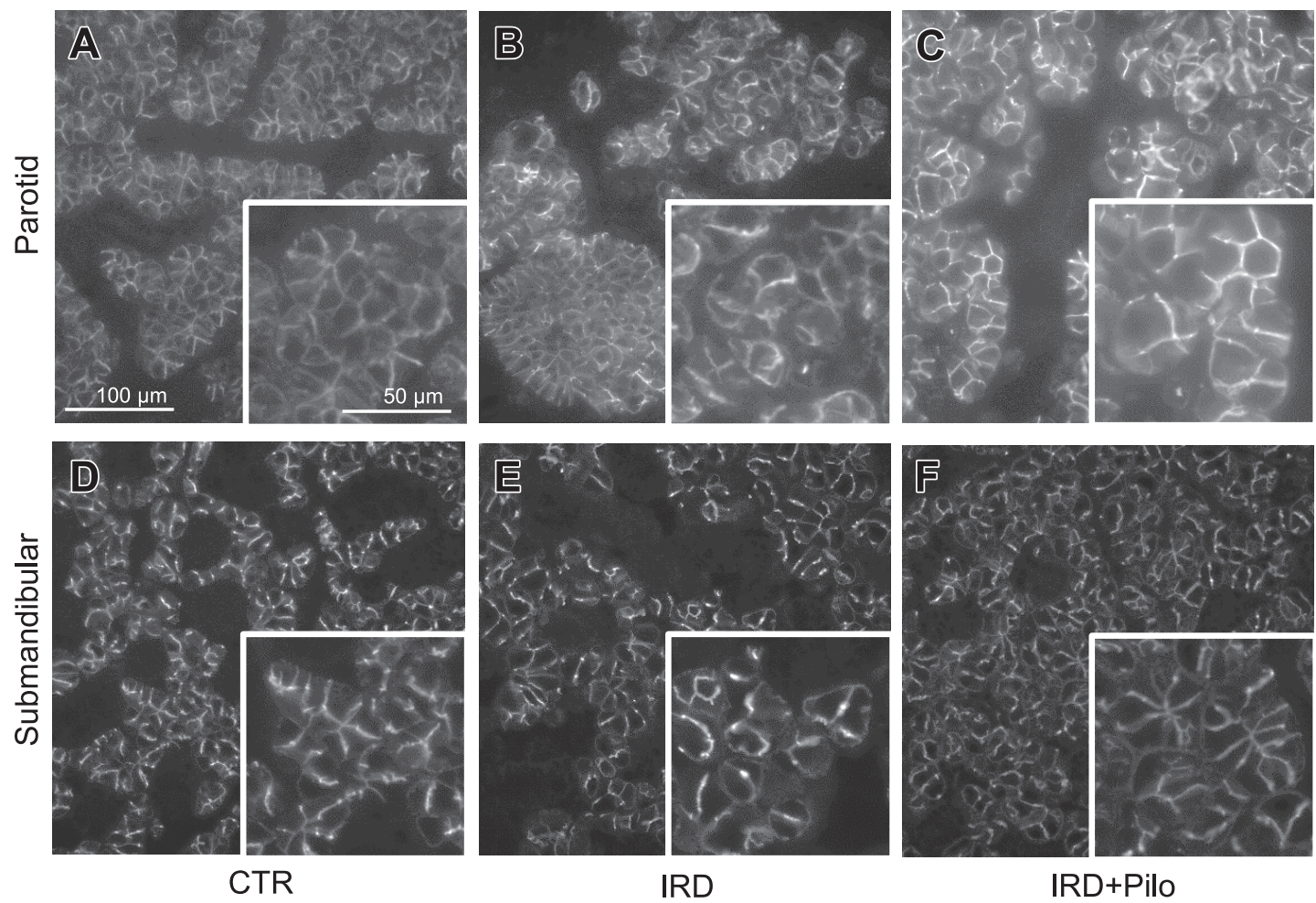

Fig. 7. Immunofluorescence analysis of AQP5. Typical fluorescence images of the parotid (A, B, and $\mathbf{C})$ and submandibular $(\mathbf{D}, \mathbf{E}$, and $\mathbf{F})$ glands from each group are shown. Each image was captured under identical conditions. Insets show higher magnification views of a section of individual images.
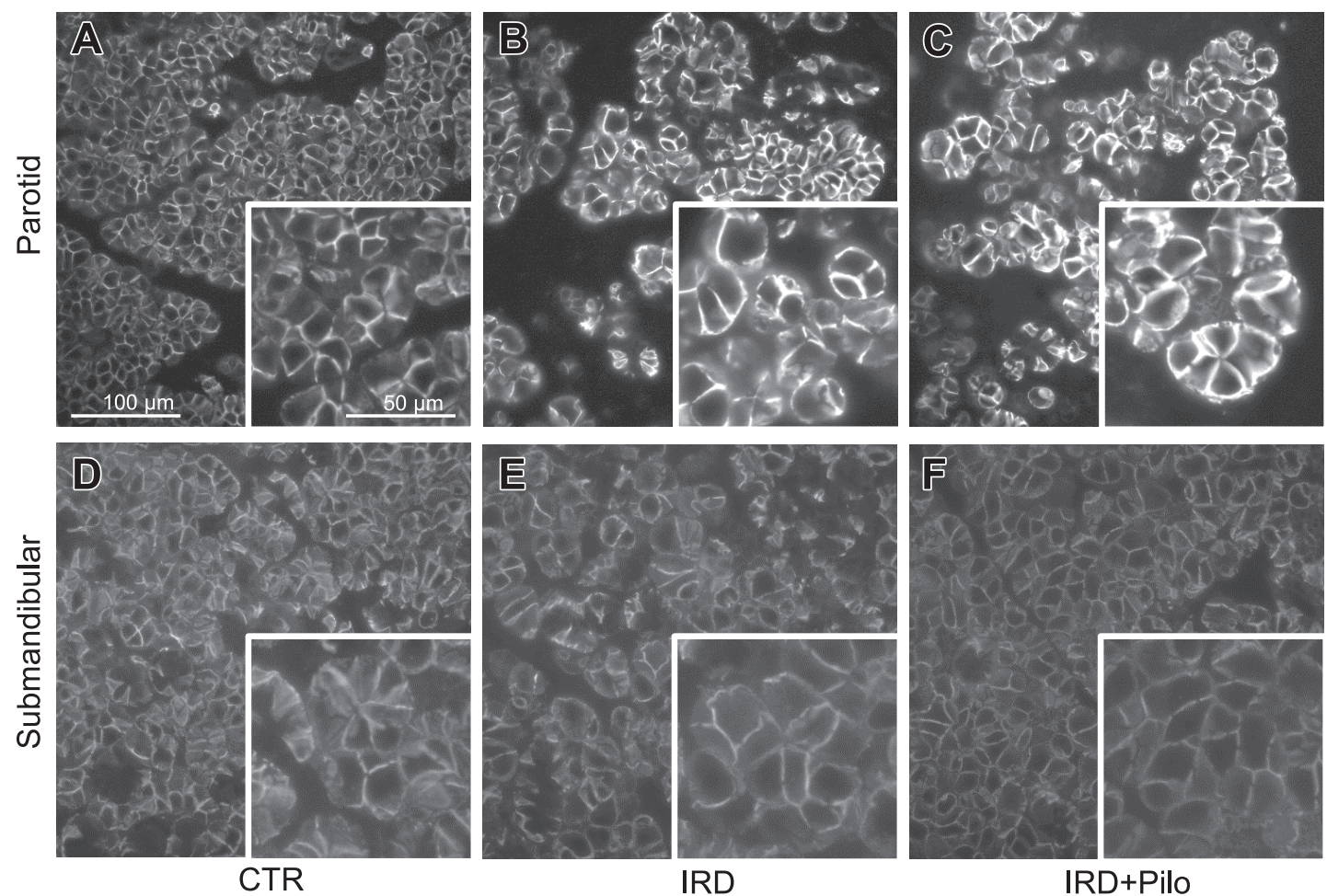

Fig. 8. Immunofluorescence analysis of NKCC1. Typical fluorescence images of the parotid $(\mathbf{A}, \mathbf{B}$, and $\mathbf{C})$ and submandibular $(\mathbf{D}, \mathbf{E}$, and $\mathbf{F})$ glands from each group are shown. Each image was captured under identical conditions. Insets show higher magnification views of a section of individual images. 

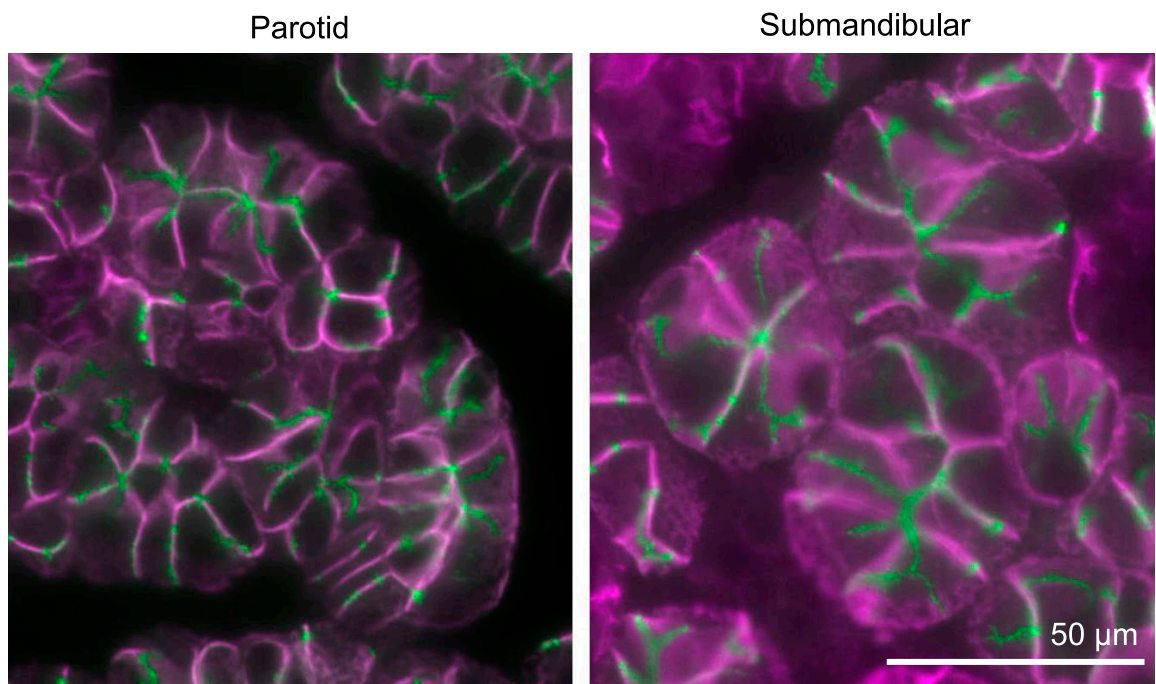

Fig. 9. Immunofluorescence localization of AQP5 and NKCC1. Double labeling with guinea pig anti-AQP5 (AffGPTM41, green) and rabbit antiNKCC1 (magenta) in the CTR parotid gland. AQP5 is localized chiefly to the apical membrane, including intercellular secretory canaliculi, and weakly to the basolateral membrane, whereas NKCC1 is chiefly localized to the basolateral membrane.

TMEM16A

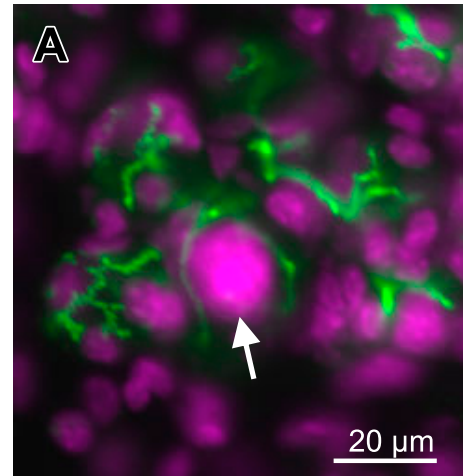

AQP5

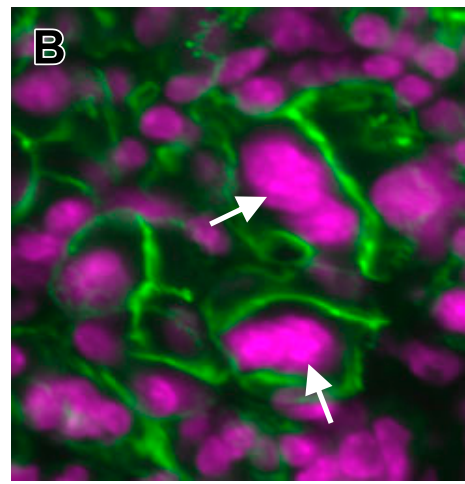

NKCC1

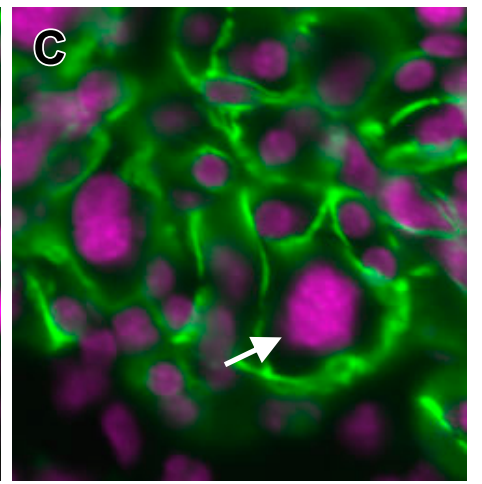

Fig. 10. Immunofluorescence localization of TMEM16A, AQP5, and NKCC1 in abnormal cells. Sections from IRD parotid glands were fluorescently labeled. Fluorescence images of TMEM16A, AQP5, and NKCC1 shown in green are merged with those for DAPI in magenta. Abnormally enlarged parotid acinar cells with enlarged nuclei are indicated by arrows.

anti-NKCC1 antibodies in the parotid and submandibular glands from the CTR group to confirm the detailed localization (Fig. 9). As a result, NKCC1 was localized mainly to the basolateral membrane, consistent with a previous study [14]. Comparison between the CTR and IRD groups showed no apparent differences both in localization and expression level for any of these functional proteins (Figs. 6, 7, and 8). Abnormally enlarged parotid acinar cells with enlarged nuclei, suggesting cellular senescence [19], were observed in the IRD group (arrowheads in Figs. 4 and 5), and these functional molecules were detected on the cell membrane at similar expression levels (Fig. 10). When we compared the IRD+Pilo with the IRD groups, no apparent difference both in the localization and expression level was found in any of these functional proteins (Figs. 6, 7, and 8).

\section{Specificity of antibodies and histochemical controls}

The anti-cleaved caspase- 3 antibody detected bands exclusively in apoptosis-induced HeLa cell homogenates. Two bands were detected (arrows in Fig. 11A), consistent with a previous study [36], in addition to a strong larger sized band of unknown origin. Positive immunofluorescence staining was detected in apoptosis-induced HeLa cells (Fig. 11D and E).

Immunoblot analysis with anti-Ki67 antibody detected a band in homogenates from proliferating $\mathrm{HeLa}$ cells (arrow in Fig. 11F), consistent with a previous study [38]. Positive immunofluorescence staining was detected in proliferating HeLa cells (Fig. $11 \mathrm{G}$ and H).

Bands were detected by the anti-TMEM16A and NKCC1 antibodies (arrows in Fig. 11K and L), consistent with previous studies $[13,34]$. 

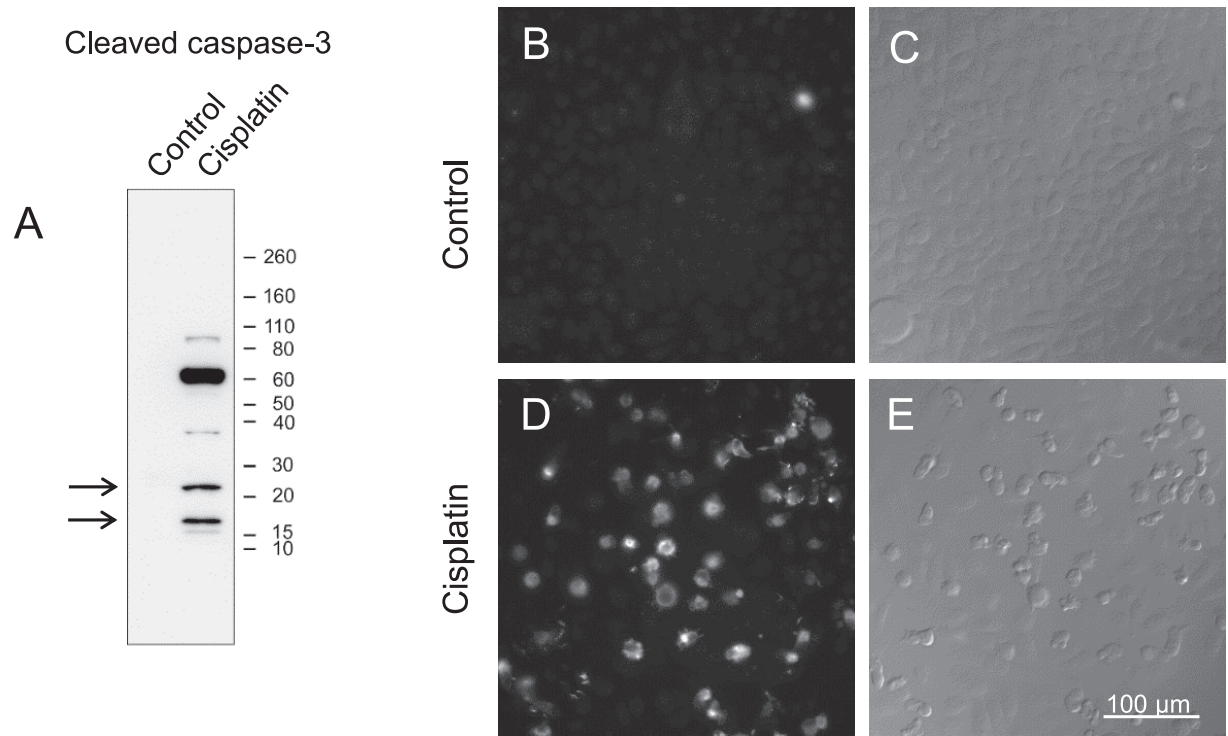

Ki67
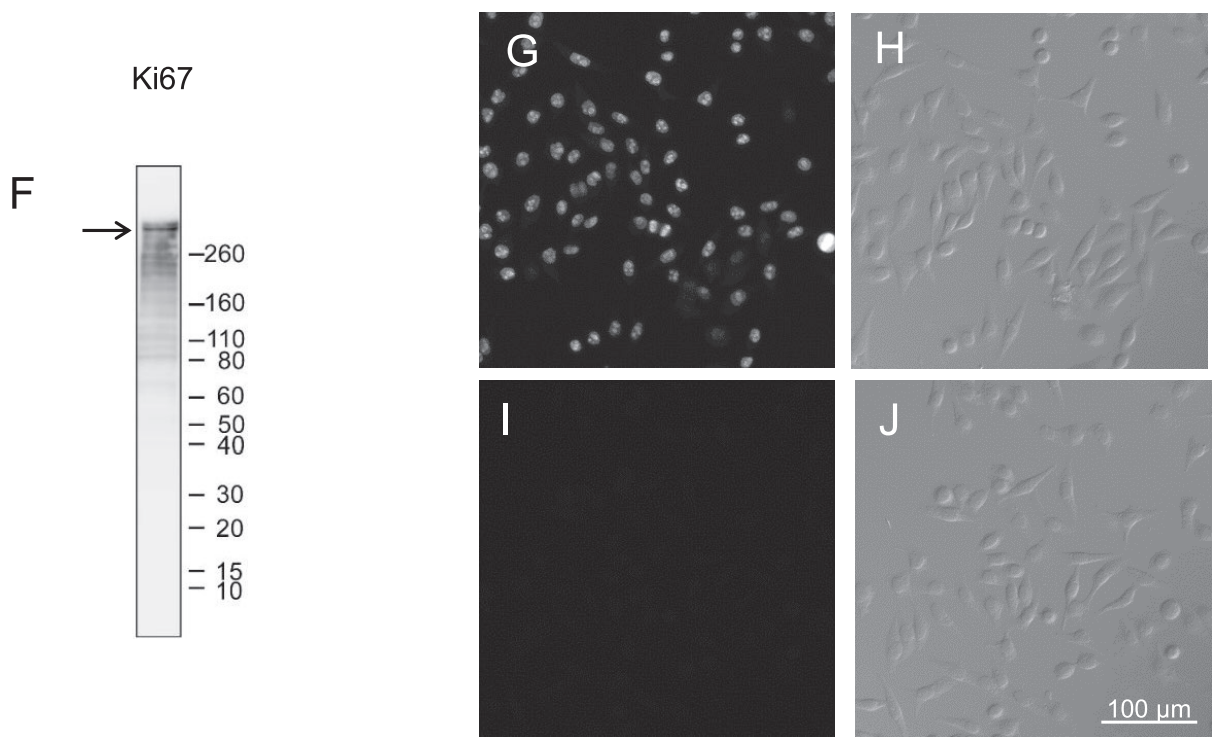

TMEM16A

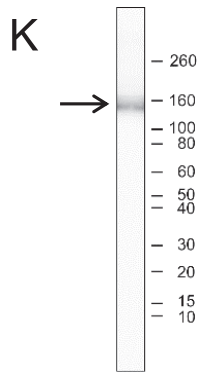

NKCC1

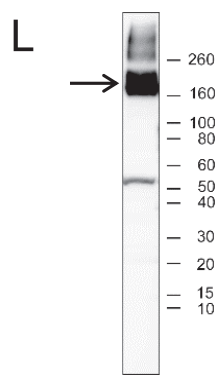

Fig. 11. Specificity of antibodies confirmed by immunoblotting and immunofluorescence. The position of Novex sharp pre-stained protein standards $(\mathrm{kDa})$ is marked on the right of each blot $(\mathbf{A}, \mathbf{F}, \mathbf{K}$, and $\mathbf{L})$. Bands near the expected size of each target protein are indicated by arrows in each blot ( $\mathbf{A}$, $\mathbf{F}, \mathbf{K}$, and $\mathbf{L}$ ). A. Immunoblotting of control HeLa and cisplatin-treated HeLa cell homogenates with cleaved caspase-3 antibody. Positive bands are only seen in cisplatin-treated HeLa cell homogenates. B-E. Immunofluorescence images of control and cisplatin-treated HeLa cells incubated with cleaved caspase-3 antibody (B and $\mathbf{D})$ and the corresponding Nomarski differential interference-contrast images (C and $\mathbf{E})$. Specific labeling is only seen in cisplatin-treated, apoptosis-induced, HeLa cells. F. Immunoblotting of HeLa cell homogenates with Ki67 antibody. G-J. Immunofluorescence images of HeLa cells incubated with (G) or without (I) Ki67 antibody and the corresponding Nomarski differential interference-contrast images $(\mathbf{H}$ and J). K, L. Immunoblotting of mouse parotid gland homogenates with TMEM16A (K) or NKCC1 (L) antibodies. 
Parotid
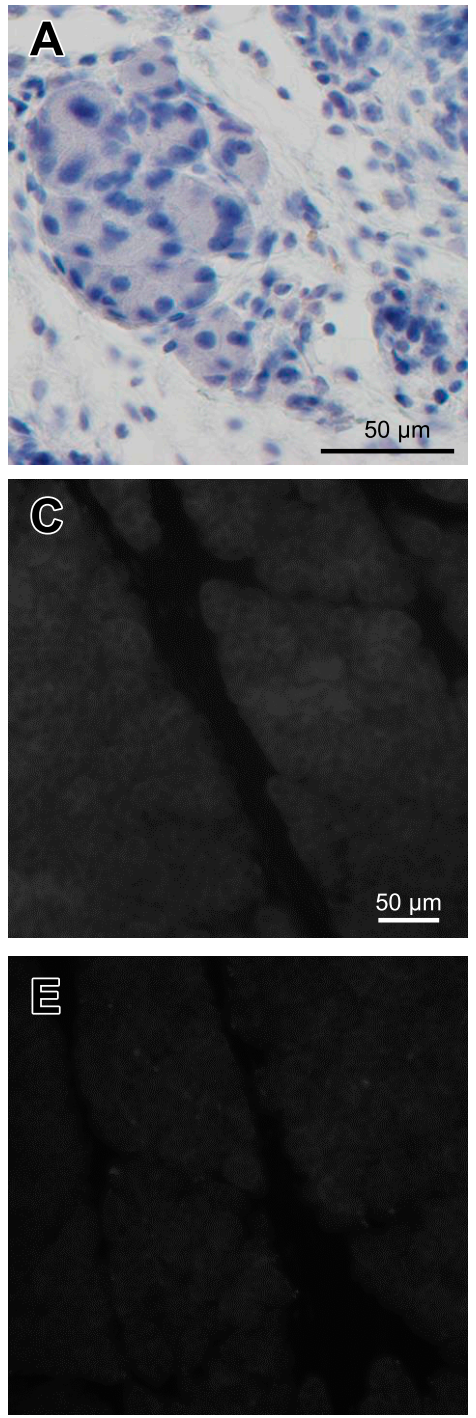

Submandibular
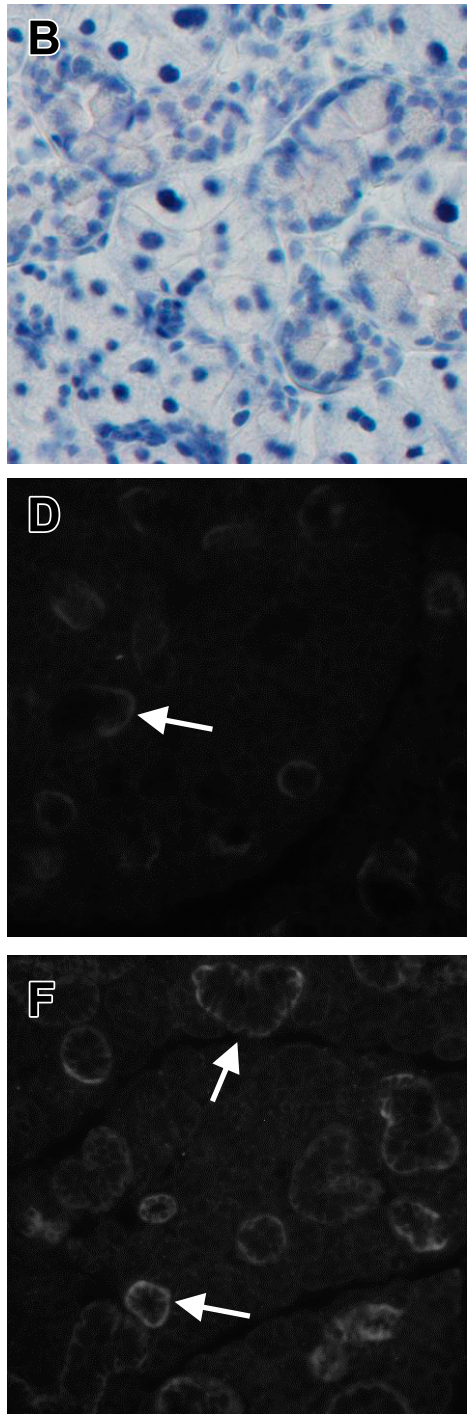

Fig. 12. Histochemical controls for immunolabeling. A, B. As a control for cleaved caspase-3 and Ki67 staining, sections from IRD parotid (A) and submandibular (B) glands were incubated with blocking solution instead of primary antibody solution. C, D. As a control for AQP5 staining, sections were incubated with antibody solution preabsorbed with an antigen peptide. E, F. As a control for TMEM16A and NKCC1 staining, sections were incubated with blocking solution instead of primary antibody solutions. Arrows indicate nonspecific labeling in ducts.

A control solution lacking primary antibodies was used to confirm the specificity of immunohistochemical staining for cleaved caspase-3 and Ki67 (Fig. 12A and B).

Preincubation of the AQP5 antibody with an immunogenic peptide $(10 \mu \mathrm{g} / \mathrm{ml})$ was performed to confirm the specificity of immunohistochemical staining; no staining was observed in acini, whereas nonspecific staining was observed in ducts (Fig. 12C and D). To confirm the specificity of immunofluorescence staining for TMEM16A and NKCC1, primary antibodies were omitted from the primary antibody solution; no specific staining was observed in acini, whereas nonspecific staining was observed in ducts (Fig. 12E and F).

\section{Discussion}

\section{Stimulated salivary flow}

To the best of our knowledge, this is the first report showing that long-term administration of pilocarpine attenuates the irradiation-induced decrease in salivary flow in mice for up to 2 months. Pilocarpine treatment for a longer period may have resulted in a higher salivary flow in these mice than in untreated irradiated mice. Coppes et al. $[7,8]$ and Takakura et al. [39] reported on the efficacy of pretreatment with pilocarpine or another muscarinic agonist, cevimeline. Coppes et al. [8] showed that pilocarpine pretreatment improves salivary flow rate in rats receiving 15 
Gy irradiation for up to 60 days, whereas it is no longer effective after 60 days. Takakura et al. [39] showed that cevimeline administration at 7 days before irradiation and 28 days after irradiation prevents the decrease in salivary flow, whereas cevimeline administered at 28 days after irradiation had no effect, suggesting that pre-treatment of cevimeline is effective for preventing the irradiationinduced decrease in salivary flow. In the present study, combined pre- and post-irradiation pilocarpine treatments were effective for improving salivary flow, although we did not examine which treatment, pre- or post-irradiation treatment, would predominantly affect it. The pilocarpine dose used in the present study, however, was approximately 10fold higher than that used clinically; therefore, the effect of lower doses of pilocarpine needs to be examined in future studies. In addition, the effect of continuous pilocarpine administration for a longer period needs to be tested to determine the duration of efficacy.

Because we measured stimulated salivary flow rather than resting flow, similar to previous studies $[7,8,10,21$, $25,39]$, a direct comparison of the present results with those obtained in humans should be performed with caution.

\section{Tissue changes including apoptosis and cellular proliferation}

We clearly showed the beneficial effect of long-term administration of pilocarpine. To understand the underlying mechanism, we examined HE-stained tissues, which showed decreased acinar areas and increased interstitial tissue in IRD parotid glands, but no apparent changes in the submandibular gland. The amount of saliva secreted from the parotid gland was approximately $30 \%$ higher than that secreted from the submandibular gland in pilocarpinestimulated mice [17], indicating that the reduced salivary flow in IRD mice may be caused by damage to the parotid gland, despite the lack of apparent damage to the submandibular gland. There were no beneficial histological changes in IRD+Pilo mice compared with IRD mice. We assessed cleaved caspase- 3 as an apoptosis marker and Ki67 as a cellular proliferation marker. Previous studies showed an increase in the apoptosis rate at 24 to $48 \mathrm{hr}$ after low-dose irradiation (2 or 5 Gy) $[2,22]$ in FVB mice. In the present study, apoptosis induction was maintained at 63 days after irradiation. Long-term administration of pilocarpine seemed to decrease apoptosis, although the effect was not statistically significant. Some more studies using a larger number samples will be required to make sure whether pilocarpine has an effect in preventing apoptosis or not, as there was no such report so far. The increased cellular proliferation in the parotid glands of the IRD group was thought to be a compensatory phenomenon for apoptosis.

In addition to apoptosis, enlarged, multinucleated cells were found in irradiated parotid glands, suggesting the presence of cellular senescence [19], consistent with a previous study showing the presence of senescent cells in irradiated submandibular cells at 8 weeks after irradiation [26].
The possible beneficial effect of pilocarpine on cellular senescence should be investigated in future studies.

\section{Functional membrane transporter and channels}

We examined the effect of pilocarpine on functional proteins. Takakura et al. [39] showed that the expression of AQP5, which was downregulated in irradiated mice, improved in response to cevimeline pre-treatment. Therefore, we investigated changes in membrane proteins involved in salivary secretion, namely, TMEM16A $[4,34]$ and NKCC1 [10] in addition to AQP5 [25, 28]. The subcellular localization and expression levels of these proteins did not differ between the IRD and CTR groups, as determined by immunofluorescence. These proteins localized to the membrane even in abnormally enlarged cells. Takakura et al. [39] showed that irradiation decreases AQP5 staining intensity at the apical membrane of submandibular acinar cells. Although expression levels were not quantified in the present study, the results suggested that the downregulation of functional proteins, including AQP5, was not directly responsible for the decrease in stimulated salivary secretion in irradiated mice. We thought that the expression levels of these functional proteins might be increased in the remaining acinar cells by daily pilocarpine administration in the IRD+Pilo group, responsible for improving salivary secretion. The expression levels of these proteins in the remaining cells, however, did not differ between the IRD and IRD + Pilo groups. Many factors affect salivary secretion. Fluid secretion is initiated by acetylcholine, which is released from parasympathetic postganglionic terminals and binds to muscarinic type 3 receptor (M3R), triggering an intracellular signaling cascade [33]. M3R could be a target of autoantibodies found in Sjögren syndrome patients [3, 18]. The expression level of M3R in xerostomia caused by irradiation should be examined in the future.

In summary, we investigated the effect of long-term pilocarpine administration in irradiated mice, and showed that long-term administration restored the decrease of stimulated salivary secretion. We also examined potential underlying factors such as apoptosis, cellular proliferation, and the expression and localization of TMEM16A, AQP5, and NKCC1. Pilocarpine may have beneficial effects by reducing apoptosis, although additional studies are required.

\section{Conflicts of Interest}

The authors declare that there are no conflicts of interest.

\section{Acknowledgments}

We are deeply grateful to Dr. Haruyasu Fujita for his great help in statistical analyses. We thank all the staff of Bioresource Center, Gunma University Graduate School of 
Medicine for their help in animal care. We also thank Y. Tajika-Takahashi and M. Shimoda for their assistance. This work was supported by JSPS KAKENHI Grant Numbers 26460267 and $18 \mathrm{~K} 06816$.

\section{References}

1. Ambudkar, I. S. (2014) $\mathrm{Ca}^{2+}$ signaling and regulation of fluid secretion in salivary gland acinar cells. Cell Calcium 55; $297-$ 305 .

2. Avila, J. L., Grundmann, O., Burd, R. and Limesand, K. H. (2009) Radiation-induced salivary gland dysfunction results from p53-dependent apoptosis. Int. J. Radiat. Oncol. Biol. Phys. 73; 523-529.

3. Bacman, S., Berra, A., Sterin-Borda, L. and Borda, E. (2001) Muscarinic acetylcholine receptor antibodies as a new marker of dry eye Sjögren syndrome. Invest. Ophthalmol. Vis. Sci. 42; $321-$ 327.

4. Catalan, M. A., Kondo, Y., Pena-Munzenmayer, G., Jaramillo, Y., Liu, F., Choi, S., Crandall, E., Borok, Z., Flodby, P., Shull, G. E. and Melvin, J. E. (2015) A fluid secretion pathway unmasked by acinar-specific Tmem16A gene ablation in the adult mouse salivary gland. Proc. Natl. Acad. Sci. U S A 112; 2263-2268.

5. Caudell, J. J., Torres-Roca, J. F., Gillies, R. J., Enderling, H., Kim, S., Rishi, A., Moros, E. G. and Harrison, L. B. (2017) The future of personalised radiotherapy for head and neck cancer. Lancet Oncol. 18; e266-e273.

6. Chambers, M. S., Garden, A. S., Kies, M. S. and Martin, J. W. (2004) Radiation-induced Xerostomia in patients with head and neck cancer: Pathogenesis, impact on quality of life, and management. Head Neck 26; 796-807.

7. Coppes, R. P., Vissink, A., Zeilstra, L. J. and Konings, A. W. (1997) Muscarinic receptor stimulation increases tolerance of rat salivary gland function to radiation damage. Int. J. Radiat. Biol. $72 ; 615-625$.

8. Coppes, R. P., Zeilstra, L. J. W., Kampinga, H. H. and Konings, A. W. T. (2001) Early to late sparing of radiation damage to the parotid gland by adrenergic and muscarinic receptor agonists. $\mathrm{Br}$. J. Cancer 85; 1055.

9. Dirix, P., Nuyts, S., Vander Poorten, V., Delaere, P. and Van den Bogaert, W. (2008) The influence of xerostomia after radiotherapy on quality of life. Support. Care Cancer 16; 171-179.

10. Evans, R. L., Park, K., Turner, R. J., Watson, G. E., Nguyen, H. V., Dennett, M. R., Hand, A. R., Flagella, M., Shull, G. E. and Melvin, J. E. (2000) Severe impairment of salivation in $\mathrm{Na}^{+} / \mathrm{K}^{+} / 2 \mathrm{Cl}^{-}$cotransporter (NKCC1)-deficient mice. J. Biol. Chem. 275; 26720-26726.

11. Fox, P. C., van der Ven, P. F., Baum, B. J. and Mandel, I. D. (1986) Pilocarpine for the treatment of xerostomia associated with salivary gland dysfunction. Oral Surg. Oral Med. Oral Pathol. 61; 243-248.

12. Guchelaar, H. J., Vermes, A. and Meerwaldt, J. H. (1997) Radiation-induced xerostomia: pathophysiology, clinical course and supportive treatment. Support. Care Cancer 5; 281-288.

13. Haas, B. R. and Sontheimer, H. (2010) Inhibition of the sodiumpotassium-chloride cotransporter isoform-1 reduces glioma invasion. Cancer Res. 70; 5597.

14. He, X., Tse, C. M., Donowitz, M., Alper, S. L., Gabriel, S. E. and Baum, B. J. (1997) Polarized distribution of key membrane transport proteins in the rat submandibular gland. Pflugers Arch. 433; 260-268

15. Jiang, M., Wei, Q., Wang, J., Du, Q., Yu, J., Zhang, L. and Dong, Z. (2006) Regulation of PUMA- $\alpha$ by p53 in cisplatin-induced renal cell apoptosis. Oncogene 25; 4056.
16. Johnson, J. T., Ferretti, G. A., Nethery, W. J., Valdez, I. H., Fox, P. C., Ng, D., Muscoplat, C. C. and Gallagher, S. C. (1993) Oral pilocarpine for post-irradiation xerostomia in patients with head and neck cancer. N. Engl. J. Med. 329; 390-395.

17. Kondo, Y., Nakamoto, T., Jaramillo, Y., Choi, S., Catalan, M. A. and Melvin, J. E. (2015) Functional differences in the acinar cells of the murine major salivary glands. J. Dent. Res. 94; 715-721.

18. Koo, N. Y., Li, J., Hwang, S. M., Choi, S. Y., Lee, S. J., Oh, S. B., Kim, J. S., Lee, E. B., Song, Y. W. and Park, K. (2008) Functional epitope of muscarinic type 3 receptor which interacts with autoantibodies from Sjögren's syndrome patients. Rheumatology (Oxford) 47; 828-833.

19. Kuilman, T., Michaloglou, C., Mooi, W. J. and Peeper, D. S. (2010) The essence of senescence. Genes Dev. 24; 2463-2479.

20. Kyaw, M. T. H., Yamaguchi, Y., Choijookhuu, N., Yano, K., Takagi, H., Takahashi, N., Synn Oo, P., Sato, K. and Hishikawa, Y. (2019) The HDAC inhibitor, SAHA, combined with cisplatin synergistically induces apoptosis in alpha-fetoprotein-producing hepatoid adenocarcinoma cells. Acta Histochem. Cytochem. 52; $1-8$.

21. Li, Z., Zhao, D., Gong, B., Xu, Y., Sun, H., Yang, B. and Zhao, $X$. (2006) Decreased saliva secretion and down-regulation of AQP5 in submandibular gland in irradiated rats. Radiat. Res. $165 ; 678-687$.

22. Limesand, K. H., Schwertfeger, K. L. and Anderson, S. M. (2006) MDM2 is required for suppression of apoptosis by activated Akt1 in salivary acinar cells. Mol. Cell. Biol. 26; 88408856.

23. Limesand, K. H., Avila, J. L., Victory, K., Chang, H. H., Shin, Y. J., Grundmann, O. and Klein, R. R. (2010) Insulin-like growth factor-1 preserves salivary gland function after fractionated radiation. Int. J. Radiat. Oncol. Biol. Phys. 78; 579-586.

24. Ma, S. J., Rivers, C. I., Serra, L. M. and Singh, A. K. (2019) Long-term outcomes of interventions for radiation-induced xerostomia: A review. World J. Clin. Oncol. 10;1-13.

25. Ma, T., Song, Y., Gillespie, A., Carlson, E. J., Epstein, C. J. and Verkman, A. S. (1999) Defective secretion of saliva in transgenic mice lacking aquaporin-5 water channels. J. Biol. Chem. 274; 20071-20074.

26. Marmary, Y., Adar, R., Gaska, S., Wygoda, A., Maly, A., Cohen, J., Eliashar, R., Mizrachi, L., Orfaig-Geva, C., Baum, B. J., Rose-John, S., Galun, E. and Axelrod, J. H. (2016) Radiationinduced loss of salivary gland function is driven by cellular senescence and prevented by IL6 modulation. Cancer Res. 76; $1170-1180$.

27. Maruyama, K. and Koshihara, N. (2006) Pharmacological and clinical profi le of pilocarpine hydrochloride (SALAGEN ${ }^{\circledR}$ Tab. 5 mg). Nippon Yakurigaku Zasshi 127; 399-407.

28. Matsuzaki, T., Suzuki, T., Koyama, H., Tanaka, S. and Takata, K. (1999) Aquaporin-5 (AQP5), a water channel protein, in the rat salivary and lacrimal glands: immunolocalization and effect of secretory stimulation. Cell Tissue Res. 295; 513-521.

29. Matsuzaki, T., Ablimit, A., Suzuki, T., Aoki, T., Hagiwara, H. and Takata, K. (2006) Changes of aquaporin 5-distribution during release and reaccumulation of secretory granules in isoproterenol-treated mouse parotid gland. J. Electron Microsc. (Tokyo) 55; 183-189.

30. Matsuzaki, T., Susa, T., Shimizu, K., Sawai, N., Suzuki, T., Aoki, T., Yokoo, S. and Takata, K. (2012) Function of the membrane water channel aquaporin-5 in the salivary gland. Acta Histochem. Cytochem. 45; 251-259.

31. Mitchell, G. C., Fillinger, J. L., Sittadjody, S., Avila, J. L., Burd, R. and Limesand, K. H. (2010) IGF1 activates cell cycle arrest following irradiation by reducing binding of $\Delta \mathrm{Np} 63$ to the $\mathrm{p} 21$ promoter. Cell Death Dis. 1; e50. 
32. Pan, H. Y., Haffty, B. G., Falit, B. P., Buchholz, T. A., Wilson, L. D., Hahn, S. M. and Smith, B. D. (2016) Supply and demand for radiation oncology in the United States: Updated projections for 2015 to 2025. Int. J. Radiat. Oncol. Biol. Phys. 96; 493-500.

33. Proctor, G. B. and Carpenter, G. H. (2007) Regulation of salivary gland function by autonomic nerves. Auton. Neurosci. 133; 3-18.

34. Romanenko, V. G., Catalan, M. A., Brown, D. A., Putzier, I., Hartzell, H. C., Marmorstein, A. D., Gonzalez-Begne, M., Rock, J. R., Harfe, B. D. and Melvin, J. E. (2010) Tmem16A encodes the $\mathrm{Ca}^{+}$-activated $\mathrm{Cl}^{-}$channel in mouse submandibular salivary gland acinar cells. J. Biol. Chem. 285; 12990-13001.

35. Shirafuji, T., Ueyama, T., Tanaka, S., Hide, I., Saito, N. and Sakai, N. (2017) Validation of anti-CSP $\alpha$, SNAP25, tyrosine hydroxylase, ubiquitin, cleaved caspase 3 , and pSer PKC motif antibodies for utilization in western blotting. Acta Histochem. Cytochem. 50; 177-180.

36. Stephenson-Famy, A., Simhan, H., Marks, J., Caritis, S. N., Jeyasuria, P., Condon, J. C. and Suresh, A. (2012) Antiapoptotic signaling via MCL1 confers resistance to caspase-3-mediated apoptotic cell death in the pregnant human uterine myocyte. Mol. Endocrinol. 26; 320-330.

37. Stiubea-Cohen, R., David, R., Neumann, Y., Krief, G., Deutsch, O., Zacks, B., Aframian, D. J. and Palmon, A. (2012) Effect of irradiation on cell transcriptome and proteome of rat submandibular salivary glands. PLoS One 7; e40636.

38. Takagi, M., Nishiyama, Y., Taguchi, A. and Imamoto, N. (2014) Ki67 antigen contributes to the timely accumulation of protein phosphatase $1 \gamma$ on anaphase chromosomes. J. Biol. Chem. 289; 22877-22887.

39. Takakura, K., Takaki, S., Takeda, I., Hanaue, N., Kizu, Y., Tonogi, M. and Yamane, G. Y. (2007) Effect of cevimeline on radiation-induced salivary gland dysfunction and AQP5 in submandibular gland in mice. Bull. Tokyo Dent. Coll. 48; 47-56.

40. Valdez, I. H., Wolff, A., Atkinson, J. C., Macynski, A. A. and Fox, P. C. (1993) Use of pilocarpine during head and neck radiation therapy to reduce xerostomia and salivary dysfunction. Cancer 71; 1848-1851.

41. Xu, Y., Li, D., Zeng, L., Wang, C., Zhang, L., Wang, Y., Yu, Y., Liu, S. and Li, Z. (2015) Proteasome inhibitor lactacystin enhances cisplatin cytotoxicity by increasing endoplasmic reticulum stress-associated apoptosis in HeLa cells. Mol. Med. Rep. 11; 189-195.

This is an open access article distributed under the Creative Commons Attribution License, which permits unrestricted use, distribution, and reproduction in any medium, provided the original work is properly cited. 